\title{
Clinical utility of varenicline for smokers with medical and psychiatric comorbidity
}

REVIEW

\section{Jon O Ebbert \\ Kirk D Wyatt \\ Ali Zirakzadeh \\ Michael V Burke \\ JT Hays}

Mayo Clinic College of Medicine, Mayo Clinic, Rochester, MN, USA

Correspondence: Jon O Ebbert

Mayo Clinic College of Medicine,

200 Ist Street Southwest, Rochester,

MN 55905, USA

Tel + I (507) 266-1944

Fax +I (507) 266-7900

Email ebbert.jon@mayo.edu
This article was published in the following Dove Press journal:

International Journal of COPD

16 November 2009

Number of times this article has been viewed
Abstract: Chronic obstructive pulmonary disease (COPD) is a costly and deadly disease afflicting an estimated 210 million people and accounting for $5 \%$ of all global deaths. Exposure to cigarette smoke is the greatest risk factor for COPD in the developed world. Smoking cessation improves respiratory symptoms and lung function and reduces mortality among patients with COPD. Cigarette smokers with COPD and other co-morbid conditions such as cardiovascular disease and psychiatric illnesses should receive comprehensive tobacco treatment interventions incorporating efficacious pharmacotherapies. Varenicline, an $\alpha_{4} \beta_{2}$ nicotinic acetylcholine receptor partial agonist, is the newest and most effective drug currently available to promote smoking cessation. In conjunction with behavioral interventions and clinical monitoring for potential side effects, varenicline offers great hope for reducing smoking-attributable death and disability.

Keywords: smoking cessation, chronic obstructive pulmonary disease, varenicline

\section{Epidemiology of COPD}

Chronic obstructive pulmonary disease (COPD) is a costly and deadly disease. In the United States alone, the disease is responsible for US\$42.6 billion in annual expenditures. ${ }^{1}$ According to the World Health Organization (WHO), 210 million people around the world have COPD, with approximately $40 \%$ of those individuals having moderate to severe disease. Each year, 3 million people die from COPD making it responsible for nearly $5 \%$ of all global deaths. By 2030, COPD is predicted to become the third leading cause of deaths worldwide. ${ }^{2}$ In low income countries, indoor air pollution from cooking and heating fuels is the leading cause of COPD. Among middle and high income countries, cigarette smoking is the most important risk factor. ${ }^{2-5}$

Observational data from a number of large studies provides a clear picture of the impact of cigarette smoking on COPD incidence. A large Dutch cohort of 40 to 65 year-old cigarette smokers observed a $8.3 \% 5$-year incidence for moderate COPD. ${ }^{6}$ A large Swedish cohort study among middle-aged and elderly patients with respiratory symptoms estimated a 10 -year incidence of $13.5 \%$ for the development of COPD. ${ }^{7}$ Another study found that one-half of all continuing smokers developed COPD by age 77.8

\section{COPD management}

The Global Initiative for Chronic Obstructive Lung Disease (GOLD) Workshop summary provides guidelines for the diagnosis of COPD $\left(\mathrm{FEV}_{1} / \mathrm{FVC}<70 \%\right)$ 
and for classification of patients by disease progression (eg, $50 \% \leq \mathrm{FEV}_{1}<80 \%$ of predicted defines moderate COPD). ${ }^{4}$ The 2008 GOLD Workshop summary defines four stages of COPD ranging from mild (Stage I) to very severe (Stage IV). ${ }^{4}$ Current standard of care for management of patients with COPD is based upon stage of disease and follows the recommendations of the GOLD Workshop (Table 1). Of all the currently available treatment options for COPD, smoking cessation has the most profound impact on the course and prognosis of this disease.

\section{Smoking cessation$$
\text { for the management of COPD }
$$

Smoking cessation in subjects with mild to moderate COPD significantly slows disease progression. Smoking cessation is associated with an attenuation of the decline in $\mathrm{FEV}_{1}$ and a decrease in all-cause and COPD-related mortality. ${ }^{9}$ The largest randomized clinical trial evaluating the long-term impact of smoking cessation on COPD was the Lung Health Study (LHS). In this study, ${ }^{10} 5887$ smokers with mild to moderate COPD were randomized to receive: 1) a smoking intervention and bronchodilator; 2) a smoking intervention and placebo; or 3) no intervention ("usual care") over 5 years. The smoking intervention included an emphatic physician recommendation to quit, group meetings focused on behavior modification, and nicotine gum. After quitting, former smokers participated in a relapse prevention program focused on coping skills. Over the 11 years of follow-up with 4517 of the original LHS participants, decline in lung function among those who continued to smoke was twice that of those who had quit. Specifically, $\mathrm{FEV}_{1}$ in men who continued to smoke declined by $66.1 \mathrm{~mL} /$ year compared to $30.2 \mathrm{~mL} /$ year for men who achieved smoking abstinence. Likewise, the decline in $\mathrm{FEV}_{1}$ among women was $54.2 \mathrm{~mL} /$ year for smokers and $21.5 \mathrm{~mL} /$ year for those who achieved smoking abstinence. ${ }^{11}$ Respiratory symptoms such as dyspnea, wheezing, chronic

Table I Summary of pharmacotherapeutic interventions for the management of COPD

\begin{tabular}{|c|c|c|c|c|c|c|}
\hline Intervention & Examples & $\begin{array}{l}\text { Used in } \\
\text { stages }\end{array}$ & Place in therapy & $\begin{array}{l}\text { Clinical } \\
\text { benefits }\end{array}$ & $\begin{array}{l}\text { Physiological } \\
\text { benefits }\end{array}$ & $\begin{array}{l}\text { Mortality } \\
\text { benefit }\end{array}$ \\
\hline Short-acting $\beta$-agonists & $\begin{array}{l}\text { Albuterol } \\
\text { Levalbuterol }\end{array}$ & $\mathrm{I}-\mathrm{IV}$ & $\begin{array}{l}\text { Monotherapy or in combination with } \\
\text { short-acting anticholinergics; taken as } \\
\text { needed }\end{array}$ & $Y^{78}$ & $Y^{78}$ & \\
\hline $\begin{array}{l}\text { Short-acting } \\
\text { anticholinergics }\end{array}$ & Ipratropium & $\mathrm{I}-\mathrm{IV}$ & $\begin{array}{l}\text { Monotherapy or in combination with } \\
\text { short-acting } \beta \text {-agonist; taken as needed }\end{array}$ & $Y^{79}$ & $Y^{10,79}$ & $N^{10}$ \\
\hline Long-acting $\beta$-agonists & $\begin{array}{l}\text { Salmeterol } \\
\text { Formoterol } \\
\text { Arformoterol }\end{array}$ & II-IV & $\begin{array}{l}\text { Monotherapy or in combination with } \\
\text { anticholinergics }\end{array}$ & $Y^{79,80}$ & $Y^{79}$ & $N^{80,81}$ \\
\hline $\begin{array}{l}\text { Long-acting } \\
\text { anticholinergics }\end{array}$ & Tiotropium & II-IV & $\begin{array}{l}\text { Monotherapy or in combination with } \\
\beta \text {-agonist }\end{array}$ & $Y^{82,83}$ & $Y^{82}$ & $N^{82}$ \\
\hline Inhaled glucocorticoids & $\begin{array}{l}\text { Fluticasone } \\
\text { Budesonide }\end{array}$ & III-IV & $\begin{array}{l}\text { In combination with long- } \\
\text { acting } \beta \text {-agonist or anticholinergics } \\
\text { May be used in COPD stages I and II } \\
\text { if patient is asthmatic }\end{array}$ & $Y^{84-86}$ & $Y^{84}$ & $N^{81}$ \\
\hline Oxygen therapy & & IV & $\begin{array}{l}\text { Supplemental therapy for patients with } \\
\text { severe, chronic hypoxemia }\end{array}$ & $Y^{85}$ & $Y^{85}$ & $Y^{86}$ \\
\hline Smoking cessation & $\begin{array}{l}\text { Behavioral therapy } \\
\text { Nicotine replacement } \\
\text { therapy } \\
\text { Bupropion } \\
\text { Varenicline }\end{array}$ & I-IV & $\begin{array}{l}\text { Strongly recommended as a goal for all } \\
\text { COPD patients who smoke, regardless } \\
\text { of disease severity or progression }\end{array}$ & $Y^{13}$ & $Y^{10,87}$ & $Y^{13}$ \\
\hline Influenza vaccination & $\begin{array}{l}\text { Trivalent inactivated } \\
\text { vaccine }\end{array}$ & I-IV & $\begin{array}{l}\text { Annual treatment to reduce incidence } \\
\text { of viral infection and related symptom } \\
\text { exacerbations }\end{array}$ & $Y^{88}$ & & \\
\hline Pneumococcal vaccine & $\begin{array}{l}\text { I4-valent pneumococcal } \\
\text { vaccine } \\
23 \text {-valent pneumococcal } \\
\text { vaccine }\end{array}$ & I-IV & $\begin{array}{l}\text { Given to reduce incidence of bacterial } \\
\text { infection and related } \\
\text { symptom exacerbations }\end{array}$ & $N^{89}$ & & $N^{89}$ \\
\hline
\end{tabular}

Abbreviations: $Y$, yes; $N$, no significant benefit. 
cough and chronic phlegm production significantly improved in participants who received a smoking intervention $(P<0.0001) .{ }^{12}$ Although less than one-quarter $(21.7 \%)$ of study subjects in the smoking intervention group achieved smoking abstinence at the end of the 5-year study (compared to $5.4 \%$ in usual care) all-cause mortality at 14 $1 / 2$-year follow-up was significantly lower among participants who received a smoking intervention compared to those who did not ( 8.83 vs 10.38 deaths per 1,000 person-years; $P=0.03$ ). Mortality due to non cancerous respiratory disease was significantly lower in the smoking intervention group than in usual care (0.56 vs 1.08 deaths per 1000 person-years, $P=0.01) .^{13}$

The findings of the LHS highlight the critical role of smoking cessation in the slowing of COPD disease progression and provides empiric support for the idea that smoking cessation is "the most important therapeutic intervention in patients with COPD."14 Pulmonary and thoracic societies universally consider smoking cessation a critical and indispensible component of COPD management. ${ }^{15-18}$ Specifically, the GOLD Workshop has identified smoking cessation as the most significant strategy for COPD risk reduction and recommends that all smokers be offered smoking cessation interventions. ${ }^{4}$

\section{Comprehensive treatment for tobacco dependence}

The United States Public Health Service (USPHS) Clinical Practice Guideline Treating Tobacco Use and Dependence concluded that strong evidence supported the use of both behavioral and pharmacotherapeutic interventions for increasing tobacco abstinence rates. The USPHS recommended the use of two types of behavioral counseling which have been consistently shown to increase smoking abstinence rates: (1) providing practical counseling such as problemsolving, and skills training; (2) providing support during a smoker's direct contact with a clinician. ${ }^{19}$

Tobacco dependence is best managed by treating it as a chronic disease: implementing systems to identify all people who smoke, providing brief treatment to all identified smokers, and arranging for more intensive interventions when needed. ${ }^{20,21}$ As with other chronic problems, relapse is the most likely outcome from any single treatment intervention. While some smokers may achieve long-term smoking abstinence ( $>6$ months) after a single attempt, many others will try to quit multiple times and repeatedly relapse. ${ }^{22,23}$ Re-engagement of patients in the quitting process is critical. Medication adjustments and behavioral support should be provided until long-term abstinence is achieved. Frequent screening at follow-up visits and the offering of new medications can build confidence and reengage patients in treatment.

\section{Identifying tobacco users}

Establishing a systematic process to identify all tobacco users is critical. To increase the likelihood of addressing tobacco use, clinicians should have tobacco use status information available before they walk in the examination room. Providing advice to quit smoking increases success, and patients who are advised to quit report higher satisfaction with clinical encounters. Although many patients are asked about smoking and advised to quit, few patients receive assistance or referral to quit. ${ }^{24}$

\section{Starting the conversation}

Communicating about smoking during a health care visit can be challenging for providers and difficult for patients. Most general practitioners acknowledge that counseling smokers to quit is important and can be effective. However, providers are frequently concerned that their interventions may negatively impact patient satisfaction despite evidence to the contrary. ${ }^{25}$ In addition, providers may have a limited repertoire of counseling skills for addressing tobacco use with patients. Qualitative studies have found that there is a tendency by general practitioners to have discussions about stopping smoking only with patients who are motivated or to limit the discussions to health problems caused by smoking. ${ }^{26}$

Most smokers are ambivalent about stopping smoking despite knowing that smoking causes health problems. Many factors conflict with the desire to stop smoking. Patients anticipate the enjoyment from cigarettes that has been strongly paired with situations and stimuli that are present throughout their day-to-day activities. Withdrawal can be quite painful and relief from withdrawal can be very positively reinforcing. Patients may have concerns about loss of self esteem if a quit attempt fails, concerns about weight gain associated with quitting, and difficulty envisioning how they will manage to "fill the void" once they stop smoking. ${ }^{27}$ The combination of limited counseling repertoire among providers and the multiple reasons underlying patient ambivalence can decrease the likelihood that patients will talk with their providers about tobacco use and even inhibit patients' reporting of tobacco related health symptoms. ${ }^{28}$ However, motivation to stop smoking can quickly change, and people who smoke can be helped to make a quit attempt despite being minimally motivated at first. ${ }^{29,30}$ 
Brief interventions adapted from Motivational Interviewing can help to engage a patient in a positive discussion about treatment options or prepare the patient to participate in more intensive treatment. ${ }^{31}$ One of the main barriers to engaging patients in an in-depth discussion of treatment options may be the difficulty in starting the conversation. A few simple questions can be effective for engaging identified smokers such as: (1) beginning with a non-judgmental open-ended question, (2) eliciting the patient's self-perceived importance and confidence for stopping, and (3) assessing past quit attempts and treatment. ${ }^{32,33}$

A useful opening question is "What are your thoughts and feelings about stopping smoking?" This can assure the patient that the physician is interested in the patient's perspective and provide useful information about a patient's self-perceived obstacles to and benefits expected from quitting smoking. The motivation to stop smoking is a function of the self-assessed importance a patient places on quitting as well as their self-efficacy for succeeding. Scaling for importance and confidence can be used to elicit and strengthen a patient's motivation to make a quit attempt and can be a function of the self-assessed importance placed upon quitting, and/or how successful the patient believes they will be if they try to quit. To assess both domains, providers can ask the following "scaling questions": "On a scale of 0 to 10 , with 0 being not important at all, how important it is for you to stop smoking?" and "On a scale of 0 to 10 , with 0 being not being not confident at all, how confident are you in your ability to stop smoking?" The provider can then follow-up by asking the patient to elaborate from his or her perspective on why it is important to quit, and share what makes them feel confident they can succeed. The provider can then join the patient to discuss options for enhancing confidence by building future success on past success. Deciding on a plan of therapy can be facilitated by asking "What has helped you in the past to stop smoking for even brief periods of time?" If a patient is willing to make a quit attempt, sufficient treatment intensity should be applied to maximize the likelihood of success.

\section{Incorporating behavioral counseling}

A dose-response relationship exists between counseling time and tobacco dependence treatment outcomes. ${ }^{34}$ Many hospitals, health departments and health care facilities have hired or trained tobacco treatment specialists (TTS). More allied health professionals are becoming certified as tobacco treatment specialists (attud.org), ${ }^{35}$ and standards for providing evidence-based treatment are becoming recognized. TTS provide assurance to the referring clinician that the tobacco use intervention is consistent with evidencebased guidelines.

If a provider does not have local evidence-based tobacco treatment programs at his or her disposal, a telephone quitline can provide support. Each state in the United States, provinces in Canada, and jurisdictions in many other countries provide tobacco treatment counseling via the telephone. The simplest way for practitioners in the United States to engage patients in the tobacco quitline is to tell patients to call 1-800QUITNOW after leaving the office. Through the National Network of Tobacco Cessation Quitlines, callers will be routed to the tobacco quitline in their state. States have differing levels of support that they can provide, and patients can receive this information when they call. Practitioners can also learn about the state-specific service offerings through the National Quitline Consortium website (naquitline.org). ${ }^{36}$ The Internet may also be effective in providing support to patients who are trying to quit smoking. A number of web sites have been developed to support quit attempts such as the American Legacy website "Become an Ex" (becomeanex. org) and Quitnet (quitnet.com). The US National Cancer Institute publishes "Clearing the Air," a comprehensive guide to quitting smoking that is designed specifically for patient use. Smokers can order a free print copy of the guide or view it online (smokefree.gov).

\section{Pharmacotherapy}

Seven "first-line" pharmacotherapies are currently available for facilitating smoking cessation: five nicotine replacement therapies (ie patch, gum, lozenge, inhaler and nasal spray), bupropion sustained-release (SR) and varenicline. Clonidine and nortriptyline have been identified as "second-line" medications. ${ }^{19}$ "First-line" medications should be selected initially because of their well-reported efficacies and favorable side effect profiles.

All of the available pharmacotherapies indicated for the treatment of smoking cessation have been shown to be effective as monotherapy and are often used as such for light smokers ( $\leq 10$ cigarettes per day). Our general approach at the Mayo Nicotine Dependence Center for moderate and heavy smokers ( $>10$ cigarettes per day) is to prescribe the nicotine patch to provide continuous dosing and the ad libitum nicotine replacement products (ie nicotine gum, nicotine nasal spray, nicotine inhaler, nicotine lozenge) to cover sudden urges and cravings. As a rough guide, the required patch dose (in milligrams) should be the same or slightly more than the number of cigarettes per day (cpd) smoked. 
For example, patients who smoke 30 cigarettes per day could be started on a nicotine patch dose of $35 \mathrm{mg} /$ day $(21 \mathrm{mg}+$ $14 \mathrm{mg}$ patches). We offer bupropion SR concomitantly if there are no contraindications. While combination therapy with multiple nicotine replacement therapies is not an FDAapproved treatment strategy, available evidence suggests that combination therapy increases smoking abstinence rates over monotherapy. ${ }^{37-40}$

Varenicline is appropriate for patients who have never tried any pharmacotherapy for smoking cessation and for those who have relapsed from abstinence using other medications. The recommended dosing for varenicline is $0.5 \mathrm{mg}$ once daily for three days, twice daily for four days, then $1 \mathrm{mg}$ twice daily for 11 weeks. Starter packs for the first month of therapy with the "ramp-up" are available in some locations. Patients should plan to quit on day 8 (Target Quit Day) of therapy, the point at which the target dose of varenicline is reached. We continue varenicline for 3 months beyond the initial 3 months if patients are at a self-identified risk for relapse. ${ }^{41}$

\section{Interventions for smokers with comorbid COPD}

Tobacco use interventions in patients with COPD have been demonstrated to be effective for increasing smoking abstinence rates. The LHS demonstrated that a combination of behavioral counseling and nicotine replacement therapy (NRT) was effective for promoting smoking cessation in COPD patients. In an 11-year follow-up of the LHS, 21.9\% of participants in the smoking intervention group achieved long-term smoking abstinence compared to $6.0 \%$ of participants in the control group $(P=0.001) .{ }^{11}$ Several other trials assessing the efficacy of pharmacotherapy for smoking cessation have been conducted in patients with COPD with mixed results. One study evaluated the efficacy of 12 weeks of bupropion SR for smoking cessation among 404 COPD patients. While bupropion SR increased smoking abstinence rates at 26 weeks compared to placebo (prolonged abstinence $16 \%$ vs $9 \%, P<0.05$ ) no statistically significant difference in abstinence rates was observed between the two treatment groups at 12 months. ${ }^{42,43}$ In contrast, in a randomized trial of 370 patients with COPD randomized to NRT (sublingual tablet) or placebo, NRT significantly increased smoking abstinence rates at 12 months compared to placebo (biochemically confirmed 7-day point prevalence smoking abstinence: $17 \%$ vs $10 \%$; odds ratio [OR]: 1.97 ; 95\% CI: 1.06 to 3.67$).{ }^{44}$ In a study evaluating the comparative efficacy of bupropion SR and nortriptyline for smoking cessation, 255 subjects with COPD or at risk for COPD were randomized to bupropion SR (150 mg twice daily), nortriptyline (75 mg once daily) or placebo for 12 weeks. Among the subjects with COPD, 26-week prolonged smoking abstinence rates were highest in the bupropion group ( $27.3 \%$ vs $21.2 \%$ nortriptyline vs $8.3 \%$ placebo $).{ }^{45}$ The only statistically significant difference in abstinence was between bupropion SR and placebo $(P=0.03)$.

\section{Varenicline for smoking cessation}

Varenicline is the newest addition to the armamentarium of pharmacotherapies for the treatment of tobacco dependence. Varenicline offers new hope to patients with COPD and other co-morbidities attempting to achieve tobacco abstinence.

\section{Pharmacology of varenicline}

The addictiveness of a drug is directly related to how rapidly it enters the central nervous system, and smoking a cigarette is the quickest way to deliver nicotine to the human body. The addictiveness of nicotine is comparable to heroin, cocaine, and alcohol. ${ }^{46}$ Nicotine "hijacks" neural networks to produce reward by affecting the release of the dopamine in the mesolimbic system of the brain. Systemically administered nicotine increases extracellular levels of dopamine in the nucleus accumbens ${ }^{47}$ by acting on nicotinic acetylcholine receptors (nAChRs). ${ }^{48}$

Neuronal $\mathrm{nAChR}$ receptors are ion channels comprised of $\alpha$ - and $\beta$-subunits. ${ }^{49}$ Six or more of these subunits $\left(\alpha_{3}, \alpha_{4}\right.$, $\alpha_{5}, \alpha_{6}, \beta_{2}$, and $\beta_{3}$ ) are expressed in the dopaminergic neurons of the midbrain. The $\alpha_{4} \beta_{2} \mathrm{nAChR}$ in the mesolimbic system plays a critical role in the reinforcing power of nicotine.

Varenicline is an oral medication synthesized from the plant alkaloid cytisine which is known to bind predominantly and with high affinity to cerebral $\alpha_{4} \beta_{2}$ nAChRs. ${ }^{50}$ Binding at the $\alpha_{4} \beta_{2}$ nAChRs as a partial agonist, ${ }^{51,52}$ varenicline stimulates the release of dopamine, which mediates the "reward" reinforcing cigarette smoking while simultaneously blocking the binding of nicotine obtained from tobacco. As a result of this activity, nicotine withdrawal symptoms and cravings are suppressed and reduced pharmacologic reward is experienced if a tobacco-dependent patient smokes a cigarette while taking varenicline.

\section{Efficacy of varenicline}

Several randomized, placebo-controlled clinical trials have demonstrated the efficacy of varenicline for increasing tobacco abstinence rates among cigarette smokers. ${ }^{41,53-59}$ Two identically designed clinical trials ${ }^{53,54}$ compared varenicline 
$1 \mathrm{mg}$ twice per day with bupropion SR $150 \mathrm{mg}$ twice per day and placebo. At end-of-treatment (12 weeks), the 7-day point prevalence smoking abstinence rates in both studies were $21 \%$ with placebo, $36 \%$ with bupropion SR and 50\% with varenicline; all pair-wise comparisons within each study were statistically significant $(P<0.001)$. After 1 year $(9$ months after treatment had stopped), point prevalence smoking abstinence rates were $28 \%{ }^{53}$ and $31 \%^{54}$ for varenicline and statistically different from placebo $(P<0.001$ for both studies). Consistent with the proposed mechanism of action, varenicline decreased the urge to smoke, negative affect, and restlessness..$^{53,54}$

Varenicline also appears to be superior to NRT. In a study of 412 patients, short-term cessation rates (4 weeks after target quit date) were observed to be higher with varenicline than with NRT (adjusted OR 1.70; 95\% CI: 1.09 to 2.67). ${ }^{60}$ In an open-label study of patients randomized to 12 weeks of varenicline or 10 weeks of the $21 \mathrm{mg} /$ day nicotine patch with tapering, the biochemically confirmed continuous abstinence rates (last 4 weeks of treatment) among 746 subjects eligible for analysis were significantly greater with varenicline compared to the nicotine patch (55.9\% vs 43.2\%; OR 1.70; 95\% CI: 1.26 to 2.28$).{ }^{61}$ Furthermore, varenicline significantly reduced craving, withdrawal, and smoking satisfaction compared to nicotine patch. A systematic review concluded that the pooled relative risk (RR) for continuous smoking abstinence at 1 year for varenicline compared to NRT is $1.31(95 \%$ CI: 1.01 to 1.71$){ }^{62}$

In a study investigating the efficacy of an additional 12 weeks of varenicline, point prevalence smoking abstinence rates were higher in the intervention group (6 months of varenicline) compared to control (3 months varenicline +3 months placebo) at week 24 (OR 2.82; 95\% CI: 2.18 to 3.64 ) and week 52 (OR 1.33; 95\% CI: 1.06 to 1.67). ${ }^{41}$ In a study investigating the long-term (52 weeks) safety of varenicline, the 7-day point prevalence smoking abstinence rate was $36.7 \%$ in the varenicline group and $7.9 \%$ in placebo. A single serious adverse event in the vareniclinetreated group (ie subcapsular cataracts) was observed. ${ }^{55}$

\section{Tolerability and safety of varenicline}

The most frequently reported adverse effects of varenicline are nausea (29.4\% vs $10 \%$ placebo), insomnia (14.3\% vs $12.4 \%)$, abnormal dreams (13.1\% vs 3.5\%), headache ( $12.8 \%$ vs $12.6 \%)$, and constipation (9\% vs $1.5 \%) .{ }^{54}$ Nausea is generally mild $(72 \%)$ to moderate $(23 \%)$ in intensity, becomes less severe with continued drug use, and causes $2.3 \%$ of patients to discontinue treatment.
Taking the medication with food can minimize nausea without decreasing the drug's bioavailability.

Within 2 years of the drug's approval, the United States Food and Drug Administration (FDA) received reports of agitation, changes in behavior, depressed mood, suicidal ideation, and attempted and completed suicide associated with varenicline use. These symptoms have started days to weeks after initiating therapy and during withdrawal of therapy. In light of these findings, the FDA issued a public health advisory ${ }^{63}$ for varenicline and advised health care providers to monitor patients for behavior and mood changes.

\section{Varenicline in smokers with medical comorbidity COPD}

A randomized, double-blind, placebo-controlled multicenter study of varenicline administered for 12 weeks with follow-up through 52 weeks was initiated in 500 subjects with spirometrically confirmed mild to moderate COPD. The study was recently completed; however, the results have not yet been published (clinicaltrials.gov registration number NCT00285012). ${ }^{64}$

\section{Cardiovascular disease}

The effect of smoking on the development and progression of coronary heart disease (CHD) is well known, and the benefit of quitting is profound. ${ }^{65,66}$ The Surgeon General of the United States has named cigarette smoking as the chief preventable cause of CHD and attributed one third of all CHD-related mortalities to smoking, noting that the CHD-related death rate is $70 \%$ greater in smokers than in nonsmokers. ${ }^{67,68}$ In a cohort study on 7735 British, middleaged men, ${ }^{69}$ the age-adjusted relative risk for sudden cardiac death (SCD) was related to smoking status. Compared to never smokers, the relative risk for SCD was significantly higher in male current smokers (RR: 2.3 ; 95\% CI: 1.2 to 4.0 ) and slightly higher among former smokers (RR: 1.4; $95 \%$ CI: 0.8 to 2.9 ).

A high degree of co-morbidity exists between cardiovascular disease (CVD; CVD includes stroke and CHD) and COPD. A population-based study of 20,296 individuals observed that, adjusting for age, sex, smoking, body mass index, race and education, individuals with severe and very severe COPD have an increased risk of CVD (OR 2.4; 95\% CI: 1.9 to 3.0$).{ }^{70}$ Among participants who continued to smoke through the 14.5 year follow-up of the LHS, CVD was the second most common cause of death, and 
lung cancer was the leading cause. ${ }^{13}$ An estimated $20 \%$ of COPD patients $\geq 65$ years of age have undiagnosed comorbid heart failure. ${ }^{71}$

Varenicline appears to be safe and effective for smokers with CHD who wish to quit. The first reported trial of varenicline use in patients with CHD was a multicenter study involving 703 participants aged 35 to 75 years randomized to varenicline (1 mg twice daily) or placebo for twelve weeks along with behavioral support. At 52 weeks, biochemically confirmed prolonged abstinence (4 week grace period) was $19.8 \%$ for varenicline and $7.4 \%$ for placebo (OR: $3.19 ; 95 \%$ CI: 1.97 to 5.18$)$. The most common adverse events related to the study drug were nausea $(29.5 \%)$, headache $(12.7 \%)$ and insomnia (11.9\%). Only $2.3 \%$ of varenicline-treated subjects discontinued the study medication as compared to $1.4 \%$ of subjects in the placebo group. The efficacy reported in this study was similar to previous trials of varenicline for smoking cessation in a general population of cigarette smokers $\left(21.9 \%\right.$ vs $8.4 \%{ }^{53}$ and $23.0 \%$ vs $\left.10.3 \%\right) .{ }^{54}$ No studies directly comparing the efficacy of varenicline with other pharmacotherapies for smoking cessation in patients with CVD have been reported.

\section{Varenicline in smokers with psychiatric comorbidity}

Because of a higher prevalence of cigarette smoking and a lower likelihood of quitting among individuals with psychiatric illness, these patients are at high risk for developing smoking-related disease. ${ }^{72}$ Unfortunately, patients with mental illness are often not included in trials investigating pharmacotherapeutic smoking interventions. ${ }^{53-57}$

However, the safety and efficacy of varenicline has been evaluated in some studies that included patients with psychiatric illnesses. Within an open-label study on a group of 412 smokers receiving treatment at a tobacco dependence clinic, 111 participants had been diagnosed with psychiatric illnesses. When data from all study participants were pooled, the biochemically confirmed smoking abstinence rates four weeks after the target quit date were higher among patients receiving varenicline than those receiving NRT (72.1\% vs 61.3\%; adjusted OR: 1.70; 95\% CI: 1.09 to 2.67$)$. Varenicline was equally efficacious and not associated with a higher incidence or severity of adverse drug reactions among patients with psychiatric comorbidity. No cases of exacerbations of mental illness were reported.$^{60}$ A comparative study on patients with and without a history of depression came to a similar conclusion about the efficacy and safety of the drug in depressed patients. ${ }^{73}$

\section{Product label warning}

Since the original FDA advisory on psychiatric health concerns related to the use of varenicline was issued in $2008,{ }^{63}$ more reports of psychiatric events possibly related to varenicline have been reported. ${ }^{74,75}$ In response to these mounting reports, the FDA called on Pfizer, the manufacturer of varenicline (branded in the US as Chantix ${ }^{\circledR}$ ) to more prominently emphasize concerns about adverse psychiatric potentially associated with the drug. ${ }^{76}$ Accordingly, Pfizer sent letters to health care professionals and updated warnings on both patient information sheets and company websites. ${ }^{77}$ The new Chantix ${ }^{\circledR}$ product label warning stresses that health care professionals should monitor patients for possible varenicline-induced psychiatric events and encourages patients to discontinue the drug and contact a physician if they experience an adverse psychiatric event. ${ }^{77}$

In a press release by the FDA, Janet Woodcock, director of the agency's Center for Drug Evaluation and Research, emphasized the need to weigh the risk of adverse events against the benefits of smoking cessation with varenicline. ${ }^{76}$ Because the exact relationship between adverse psychiatric events and varenicline is unclear, the FDA concluded that Pfizer will have to conduct a trial to assess the prevalence of psychiatric adverse events in patients taking the drug. ${ }^{76}$

\section{Conclusions}

Given the health risks associated with smoking and the relationship between smoking status and the progression of COPD and the incidence of CHD, all patients with COPD and CHD who smoke should be offered a comprehensive smoking cessation intervention. Patients with psychiatric illnesses have a higher prevalence of smoking and may have a difficult time quitting. The most effective pharmacologic intervention available is varenicline; however, prescribers should closely monitor patients due to the possibility that the drug may cause psychiatric instability. Behavioral intervention should also be incorporated into every patient's treatment plan. When face-to-face counseling is not available or feasible, telephone quit lines and self-help guides can offer support for smokers as they make a quit attempt.

\section{Disclosures}

JTH has received support from Pfizer to conduct a clinical trial of varenicline.

\section{Acknowledgments}

This project was supported by Award Number CA 132621 (Ebbert) from the National Cancer Institute. The content is solely the responsibility of the authors and does not 
necessarily represent the official views of the National Cancer Institute or the National Institutes of Health.

\section{References}

1. Morbidity and Mortality: 2007 Chart Book on Cardiovascular, Lung, and Blood Diseases. In: Institute NHLaB, ed; 2007.

2. Chronic Obstructive Lung Disease (COPD): World Health Organization; 2008. Fact sheet \#315.

3. Mannino DM. COPD: epidemiology, prevalence, morbidity and mortality, and disease heterogeneity. Chest. 2002;121(5 Suppl): 121S-126S.

4. Global Strategy for Diagnosis, Management, and Prevention of COPD. Global Initiative for Chronic Obstructive Lung Disease (GOLD). http://www.goldcopd.org. Accessed 29 Jun, 2009.

5. Standards for the diagnosis and care of patients with chronic obstructive pulmonary disease. American Thoracic Society. Am J Respir Crit Care Med. 1995;152(5 Pt 2):S77-S121.

6. Geijer RM, Sachs AP, Verheij TJ, Salome PL, Lammers JW, Hoes AW. Incidence and determinants of moderate COPD (GOLD II) in male smokers aged 40-65 years: 5-year follow up. Br J Gen Pract. 2006; 56(530):656-661.

7. Lindberg A, Jonsson AC, Ronmark E, Lundgren R, Larsson LG, Lundback B. Ten-year cumulative incidence of COPD and risk factors for incident disease in a symptomatic cohort. Chest. 2005;127(5): 1544-1552.

8. Lundback B, Lindberg A, Lindstrom M, et al. Not 15 but $50 \%$ of smokers develop COPD? - Report from the Obstructive Lung Disease in Northern Sweden Studies. Respir Med. 2003;97(2):115-122.

9. Godtfredsen NS, Lam TH, Hansel TT, et al. COPD-related morbidity and mortality after smoking cessation: status of the evidence. Eur Respir J. 2008;32(4):844-853.

10. Anthonisen NR, Connett JE, Kiley JP, et al. Effects of smoking intervention and the use of an inhaled anticholinergic bronchodilator on the rate of decline of FEV . The Lung Health Study. JAMA. 1994;272(19): $1497-1505$.

11. Anthonisen NR, Connett JE, Murray RP. Smoking and lung function of Lung Health Study participants after 11 years. Am J Respir Crit Care Med. 2002;166(5):675-679.

12. Kanner RE, Connett JE, Williams DE, Buist AS. Effects of randomized assignment to a smoking cessation intervention and changes in smoking habits on respiratory symptoms in smokers with early chronic obstructive pulmonary disease: the Lung Health Study. Am J Med. 1999;106(4):410-416.

13. Anthonisen NR, Skeans MA, Wise RA, Manfreda J, Kanner RE, Connett JE. The effects of a smoking cessation intervention on 14.5-year mortality: a randomized clinical trial. Ann Intern Med. 2005; 142(4):233-239.

14. Rabe KF, Beghe B, Luppi F, Fabbri LM. Update in Chronic Obstructive Pulmonary Disease 2006. Am J Respir Crit Care Med. 2007;175(12):1222-1232.

15. Celli BR, MacNee W, Agusti A, et al. Standards for the diagnosis and treatment of patients with COPD: a summary of the ATS/ERS position paper. Eur Respir J. 2004;23(6):932-946.

16. Tonnesen P, Carrozzi L, Fagerstrom KO, et al. Smoking cessation in patients with respiratory diseases: a high priority, integral component of therapy. Eur Respir J. 2007;29(2):390-417.

17. O'Donnell DE, Aaron S, Bourbeau J, et al. Canadian Thoracic Society recommendations for management of chronic obstructive pulmonary disease - 2007 update. Can Respir J. 2007;14 Suppl B:5B-32B.

18. Smoking and health: a physician's responsibility. A statement of the joint committee on smoking and health. American College of Chest Physicians, American Thoracic Society, Asia Pacific Society of Respirology, Canadian Thoracic Society, European Respiratory Society, International Union Against Tuberculosis and Lung Disease. Eur Respir J. 1995;8(10):1808-1811.
19. Fiore MC, Bailey WC, Cohen S, et al. Treating Tobacco Use and Dependence: Clinical Practice Guideline. Rockville, MD: US: US Department of Health and Human Services, Public Health Service; 2008.

20. Kohler CL, Bailey WC. Tobacco dependence: a chronic disease. Chest. 2002;121(3):686-687.

21. Steinberg MB, Schmelzer AC, Richardson DL, Foulds J. The case for treating tobacco dependence as a chronic disease. Ann Intern Med. 2008;148(7):554-556.

22. Hughes JR, Keely J, Naud S. Shape of the relapse curve and long-term abstinence among untreated smokers. Addiction. 2004;99(1):29-38.

23. Yudkin P, Hey K, Roberts S, Welch S, Murphy M, Walton R. Abstinence from smoking eight years after participation in randomised controlled trial of nicotine patch. BMJ. 2003;327(7405):28-29.

24. Cokkinides V, Bandi P, Ward E, Jemal A, Thun M. Progress and Opportunities in Tobacco Control. CA Cancer J Clin. 2006;56(3): $135-142$.

25. Conroy MB, Majchrzak NE, Regan S, Silverman CB, Schneider LI, Rigotti NA. The association between patient-reported receipt of tobacco intervention at a primary care visit and smokers' satisfaction with their health care. Nicotine Tob Res. 2005;7 Supp1 1:S29-S34.

26. Coleman T, Cheater F, Murphy E. Qualitative study investigating the process of giving anti-smoking advice in general practice. Patient Educ Couns. 2004 Feb;52(2):159-163.

27. Aveyard P, West R. Managing smoking cessation. BMJ. 2007;335(7609): $37-41$.

28. Butler CC, Pill R, Stott NC. Qualitative study of patients' perceptions of doctors' advice to quit smoking: implications for opportunistic health promotion. BMJ. 1998;316(7148):1878-1881.

29. West R, Sohal T. "Catastrophic" pathways to smoking cessation: findings from national survey. BMJ. 2006;332(7539):458-460.

30. Pisinger C, Vestbo J, Borch-Johnsen K, Jorgensen T. It is possible to help smokers in early motivational stages to quit. The Inter99 study. Prev Med. 2005;40(3):278-284.

31. Dunn C, Deroo L, Rivara FP. The use of brief interventions adapted from motivational interviewing across behavioral domains: a systematic review. Addiction. 2001;96(12):1725-1742.

32. Gance-Cleveland B. Motivational interviewing: improving patient education. J Pediatr Health Care. 2007;21(2):81-88.

33. Burke MV, Ebbert JO, Hays JT. Treatment of tobacco dependence. Mayo Clin Proc. 2008;83(4):479-483; quiz 483-474.

34. Fiore M, Bailey W, Cohen S, et al. Treating Tobacco Use and Dependence: Clinical Practice Guideline. Rockville, MD: US Department of Health and Human Services. Public Health Service; 2000.

35. Pbert L. Healthcare provider training in tobacco treatment: building competency. Am J Med Sci. 2003;326(4):242-247.

36. US Quitline Facts. North American Quitline Consortium. http://www. naquitline.org. Accessed 27 Feb 2008.

37. Kornitzer M, Boutsen M, Dramaix M, Thijs J, Gustavsson G. Combined use of nicotine patch and gum in smoking cessation: a placebocontrolled clinical trial. Prev Med. 1995;24(1):41-47.

38. Blondal T, Gudmundsson LJ, Olafsdottir I, Gustavsson G, Westin A. Nicotine nasal spray with nicotine patch for smoking cessation: randomized trial with six year follow up. BMJ. 1999;318: 285-288.

39. Jorenby DE, Leischow SJ, Nides M, et al. A controlled trial of sustainedrelease bupropion, a nicotine patch, or both for smoking cessation. N Engl J Med. 1999;340(9):685-691.

40. Croghan IT, Hurt RD, Dakhil SR, et al. Randomized comparison of a nicotine inhaler and bupropion for smoking cessation and relapse prevention. Mayo Clin Proc. 2007;82(2):186-195.

41. Tonstad S, Tønnesen P, Hajek P, Williams KE, Billing CB, Reeves KR. Effect of maintenance therapy with varenicline on smoking cessation: a randomized controlled trial. JAMA. 2006;296(1):64-71.

42. Tashkin DP, Kanner R, Bailey W, et al. Smoking cessation in patients with chronic obstructive pulmonary disease: a double-blind, placebocontrolled, randomised trial. Lancet. 2001;357(9268):1571-1575. 
43. Wagena EJ, van der Meer RM, Ostelo RJ, Jacobs JE, van Schayck CP. The efficacy of smoking cessation strategies in people with chronic obstructive pulmonary disease: results from a systematic review. Respir Med. 2004;98(9):805-815.

44. Tonnesen P, Mikkelsen K, Bremann L. Nurse-conducted smoking cessation in patients with COPD using nicotine sublingual tablets and behavioral support. Chest. 2006;130(2):334-342.

45. Wagena EJ, Knipschild PG, Huibers MJ, Wouters EF, van Schayck CP. Efficacy of bupropion and nortriptyline for smoking cessation among people at risk for or with chronic obstructive pulmonary disease Arch Intern Med. 2005;165(19):2286-2292.

46. Stolerman IP, Jarvis MJ. The scientific case that nicotine is addictive Psychopharmacology (Berl). 1995;117(1):2-10; discussion 14-20.

47. Pontieri FE, Tanda G, Orzi F, Di Chiara G. Effects of nicotine on the nucleus accumbens and similarity to those of addictive drugs. Nature. 1996;382(6588):255-257.

48. Dani JA, Heinemann S. Molecular and cellular aspects of nicotine abuse. Neuron. 1996;16(5):905-908.

49. Corringer PJ, Le Novere N, Changeux JP. Nicotinic receptors at the amino acid level. Annu Rev Pharmacol Toxicol. 2000;40:431-458.

50. Smith JW, Mogg A, Tafi E, et al. Ligands selective for $\alpha_{4} \beta_{2}$ but not $\alpha_{3} \beta_{4}$ or $\alpha_{7}$ nicotinic receptors generalise to the nicotine discriminative stimulus in the rat. Psychopharmacology (Berl). 2007;190(2): $157-170$.

51. Coe JW, Brooks PR, Vetelino MG, et al. Varenicline: an $\alpha_{4} \beta_{2}$ nicotinic receptor partial agonist for smoking cessation. J Med Chem. 2005;48(10):3474-3477.

52. Lesage MG, Shelley D, Ross JT, Carroll FI, Corrigall WA. Effects of the nicotinic receptor partial agonists varenicline and cytisine on the discriminative stimulus effects of nicotine in rats. Pharmacol Biochem Behav. 2009;91(3):461-467.

53. Gonzales D, Rennard SI, Nides M, et al. Varenicline, an $\alpha_{4} \beta_{2}$ nicotinic acetylcholine receptor partial agonist, vs sustained-release bupropion and placebo for smoking cessation: a randomized controlled trial JAMA. 2006;296(1):47-55.

54. Jorenby DE, Hays JT, Rigotti NA, et al. Efficacy of varenicline, an $\alpha_{4} \beta_{2}$ nicotinic acetylcholine receptor partial agonist, vs placebo or sustainedrelease bupropion for smoking cessation: a randomized controlled trial. JAMA. 2006;296(1):56-63

55. Williams KE, Reeves KR, Billing CB Jr, Pennington AM, Gong J. A double-blind study evaluating the long-term safety of varenicline for smoking cessation. Curr Med Res Opin. 2007;23(4):793-801.

56. Oncken C, Gonzales D, Nides M, et al. Efficacy and safety of the novel selective nicotinic acetylcholine receptor partial agonist, varenicline, for smoking cessation. Arch Intern Med. 2006;166(15):1571-1577.

57. Nides M, Oncken C, Gonzales D, et al. Smoking cessation with varenicline, a selective $\alpha_{4} \beta_{2}$ nicotinic receptor partial agonist: results from a 7-week, randomized, placebo- and bupropion-controlled trial with 1-year follow-up. Arch Intern Med. 2006;166(15): 1561-1568.

58. Tsai ST, Cho HJ, Cheng HS, et al. A randomized, placebo-controlled trial of varenicline, a selective $\alpha_{4} \beta_{2}$ nicotinic acetylcholine receptor partial agonist, as a new therapy for smoking cessation in Asian smokers. Clin Ther. 2007;29(6):1027-1039

59. Nakamura M, Oshima A, Fujimoto $Y$, Maruyama N, Ishibashi T, Reeves KR. Efficacy and tolerability of varenicline, an $\alpha_{4} \beta_{2}$ nicotinic acetylcholine receptor partial agonist, in a 12 -week, randomized, placebo-controlled, dose-response study with 40-week follow-up for smoking cessation in Japanese smokers. Clin Ther. 2007;29(6): 1040-1056.

60. Stapleton JA, Watson L, Spirling LI, et al. Varenicline in the routine treatment of tobacco dependence: a pre-post comparison with nicotine replacement therapy and an evaluation in those with mental illness. Addiction. 2008;103(1):146-154.

61. Aubin HJ, Bobak A, Britton JR, et al. Varenicline versus transdermal nicotine patch for smoking cessation: results from a randomised open-label trial. Thorax. 2008;63(8):717-724.
62. Cahill K, Stead LF, Lancaster T. Nicotine receptor partial agonists for smoking cessation. Cochrane Database Syst Rev. 2008;(3): CD006103.

63. US Food and Drug Administration. Public Health Advisory: Important Information on Chantix (varenicline). http://www.fda.gov/CDER/Drug/ advisory/varenicline.htm. Accessed October 2, 2008.

64. Smoking cessation in subjects with mild-to-moderate chronic obstructive pulmonary disease (COPD) (ClinicalTrials.gov identifier: NCT00285012). http://clinicaltrials.gov/ct2/show/NCT00285012. Accessed 18 Jun, 2009.

65. McRobbie H, Thornley S. The importance of treating tobacco dependence. Rev Esp Cardiol. 2008;61(6):620-628.

66. Ambrose JA, Barua RS. The pathophysiology of cigarette smoking and cardiovascular disease: an update. J Am Coll Cardiol. 2004;43(10): 1731-1737.

67. Office on Smoking and Health. The health consequences of smoking: cardiovascular disease. A report of the surgeon general. Rockville, Maryland: Health Service, US Department of Health and Human Services; 1983.

68. US Department of Health and Human Services, Centers for Disease Control and Prevention, National Center for Chronic Disease Prevention and Health Promotion, Office on Smoking and Health. The Health Consequences of Smoking: A Report of the Surgeon General. Atlanta; 2004.

69. Wannamethee G, Shaper AG, Macfarlane PW, Walker M. Risk factors for sudden cardiac death in middle-aged British men. Circulation. 1995;91(6):1749-1756.

70. Mannino DM, Thorn D, Swensen A, Holguin F. Prevalence and outcomes of diabetes, hypertension and cardiovascular disease in COPD. Eur Respir J. 2008;32(4):962-969.

71. Rutten FH, Cramer MJM, Grobbee DE, et al. Unrecognized heart failure in elderly patients with stable chronic obstructive pulmonary disease. Eur Heart J. 2005;26(18):1887-1894.

72. Lasser K, Boyd JW, Woolhandler S, Himmelstein DU, McCormick D, Bor DH. Smoking and Mental Illness: A Population-Based Prevalence Study. JAMA. 2000;284(20):2606-2610.

73. McClure JB, Swan GE, Jack L, et al. Mood, side-effects and smoking outcomes among persons with and without probable lifetime depression taking varenicline. J Gen Intern Med. 2009;24(5):563-569.

74. Alhatem F, Black JE. Varenicline-induced mania in a bipolar patient. Clin Neuropharmacol. 2009;32(2):117-118.

75. Kutscher EC, Stanley M, Oehlke K. Chantix-induced mental status changes in a young healthy female. S D Med. 2009;62(5):193, 195.

76. US Food and Drug Administration. Press Announcement: FDA: Boxed Warning on Serious Mental Health Events to be Required for Chantix and Zyban; 2009.

77. Pfizer I. Press Release: Pfizer Updates CHANTIX ${ }^{\circledR}$ (varenicline) Labeling in the United States: Provides Specific Instruction to Physicians and Patients About Quitting Smoking with CHANTIX 2009.

78. Ram FS, Sestini P. Regular inhaled short acting $\beta_{2}$ agonists for the management of stable chronic obstructive pulmonary disease: Cochrane systematic review and meta-analysis. Thorax. 2003;58(7):580-584.

79. Wadbo M, Lofdahl CG, Larsson K, et al. Effects of formoterol and ipratropium bromide in COPD: a 3-month placebo-controlled study. Eur Respir J. 2002;20(5):1138-1146.

80. Sin DD, McAlister FA, Man SFP, Anthonisen NR. Contemporary Management of Chronic Obstructive Pulmonary Disease: Scientific Review. JAMA. 2003;290(17):2301-2312.

81. Calverley PM, Anderson JA, Celli B, et al. Salmeterol and fluticasone propionate and survival in chronic obstructive pulmonary disease. N Engl J Med. 2007;356(8):775-789.

82. Barr RG, Bourbeau J, Camargo CA, Ram FS. Tiotropium for stable chronic obstructive pulmonary disease: A meta-analysis. Thorax. 2006;61(10):854-862.

83. Tashkin DP, Celli B, Senn S, et al. A 4-year trial of tiotropium in chronic obstructive pulmonary disease. $N$ Engl J Med. 2008;359(15): 1543-1554. 
84. Nannini L, Cates CJ, Lasserson TJ, Poole P. Combined corticosteroid and long-acting beta-agonist in one inhaler versus placebo for chronic obstructive pulmonary disease. Cochrane Database Syst Rev. 2007;(4): CD003794.

85. Bradley JM, Lasserson T, Elborn S, Macmahon J, O’Neill B. A systematic review of randomized controlled trials examining the short-term benefit of ambulatory oxygen in COPD. Chest. 2007;131(1):278-285.

86. Cranston JM, Crockett AJ, Moss JR, Alpers JH. Domiciliary oxygen for chronic obstructive pulmonary disease. Cochrane Database Syst Rev. 2005;(4):CD001744.
87. Scanlon PD, Connett JE, Waller LA, Altose MD, Bailey WC, Buist AS. Smoking cessation and lung function in mild-to-moderate chronic obstructive pulmonary disease. The Lung Health Study. Am J Respir Crit Care Med. 2000;161(2 Pt 1):381-390.

88. Poole PJ, Chacko E, Wood-Baker RW, Cates CJ. Influenza vaccine for patients with chronic obstructive pulmonary disease. Cochrane Database Syst Rev. 2006;(1):CD002733.

89. Granger R, Walters J, Poole PJ, et al. Injectable vaccines for preventing pneumococcal infection in patients with chronic obstructive pulmonary disease. Cochrane Database Syst Rev. 2006;(4):CD001390.

\section{Publish your work in this journal}

The International Journal of COPD is an international, peer-reviewed journal of therapeutics and pharmacology focusing on concise rapid reporting of clinical studies and reviews in COPD. Special focus is given to the pathophysiological processes underlying the disease, intervention programs, patient focused education, and self management protocols.

\section{Dovepress}

This journal is indexed on PubMed Central, MedLine and CAS. The manuscript management system is completely online and includes a very quick and fair peer-review system, which is all easy to use. Visit http://www.dovepress.com/testimonials.php to read real quotes from published authors.

Submit your manuscript here: http://www.dovepress.com/international-journal-of-copd-journal 